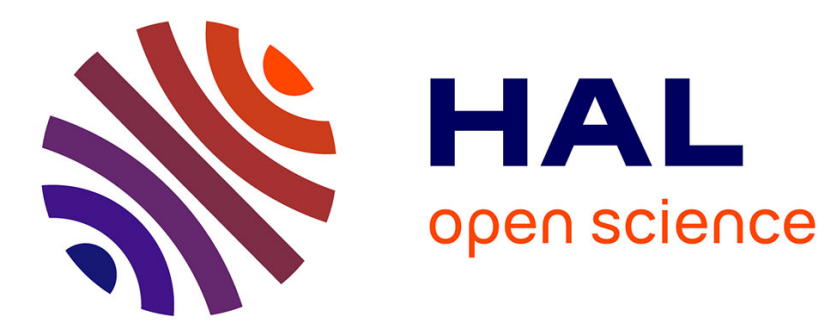

\title{
Sample environment at low temperatures
}

\author{
K. Neumaier
}

\section{To cite this version:}

K. Neumaier. Sample environment at low temperatures. Revue de Physique Appliquée, 1984, 19 (9), pp.677-683. 10.1051/rphysap:01984001909067700 . jpa-00245237

\section{HAL Id: jpa-00245237 https://hal.science/jpa-00245237}

Submitted on 1 Jan 1984

HAL is a multi-disciplinary open access archive for the deposit and dissemination of scientific research documents, whether they are published or not. The documents may come from teaching and research institutions in France or abroad, or from public or private research centers.
L'archive ouverte pluridisciplinaire HAL, est destinée au dépôt et à la diffusion de documents scientifiques de niveau recherche, publiés ou non, émanant des établissements d'enseignement et de recherche français ou étrangers, des laboratoires publics ou privés. 


\title{
Sample environment at low temperatures
}

\author{
K. Neumaier \\ Walther-Meissner-Institut für Tieftemperaturforschung, Walther-Meißner-straße 8, \\ D-8046 Garching, F.R.G.
}

\begin{abstract}
Résumé. - Des techniques de basses températures utilisées dans des études de la diffusion de neutrons sont présentées. Des méthodes de mesures de températures, en particulier avec des résistances de carbone, sont discutées. Des problèmes de transfert de chaleur sont traités en détail pour différentes sortes d'échantillons et quelques solutions possibles sont proposées.
\end{abstract}

Abstract. - A review of low temperature techniques as applied to neutron scattering studies is presented. Methods of temperature measurements especially carbon thermometry are discussed. Problems of heat transfer are treated in detail for different kind of samples and some solutions are proposed.

The number of neutron scattering studies at temperatures below $1 \mathrm{~K}$ increased considerably during the last years. The experimentalist wishing to pursue these studies must solve several technical difficulties : how to reach these temperatures, how to measure them, and how to transfer cold from the source to the sample. With the availability of dilution refrigerators capable of maintaining temperatures even below $5 \mathrm{mK}$ the first problem is more or less solved. On the other hand, the problems of temperature measurement and thermal contact must in each case be studied individually. In this paper some possibilities of how to treat these problems will be presented. Much of the content of this paper is based on several excellent books and extensive review papers [1-7].

\section{Thermometry.}

In principle, every physical property which changes with temperature could be employed as a thermometric parameter. In practice, however, the physical property used has to fulfil several rather stringent requirements : the parameter must be easily, quickly and accurately measurable, its temperature dependence should be sufficiently simple, or at least well accounted by the theory, the sensitivity of the thermometer must be high, its response time short and its heat capacity low, and the energy input due to temperature measurement must be very small.

Resistance sensors fulfil these conditions and play an important role in temperature measurements down to very low temperatures $(5 \mathrm{mK})$ in spite of the fact that the absolute value of the resistance must be calibrated independently at some temperature.

Two types of resistance elements are now in use : carbon [7] in the form of radio resistors and heavily doped germanium and silicon $[8,9]$. Metals, both pure and alloys, do not vary enough with temperature below $1 \mathrm{~K}$ to make them useful.

1.1 CARbon Resistors. - Two brands of resistors are used below $0.1 \mathrm{~K}$ : the popular Speer resistor $1 / 2 \mathrm{~W}$, Grade 1002 [7] and the Matsushita resistor (1/8 W, ERC-18 SG) with smaller physical size and smaller heat capacity than Speer resistors [10]. Unfortunately, the former is no longer manufactured, but the National Magnet Laboratory, MIT, has maintained a stock of 100,220 and $470 \Omega$ resistors for the low temperature community [11]. The major problem in the use of resistors is the difficulty in achieving thermal contact below $100 \mathrm{mK}$. This problem is highly exacerbating due to the inherent necessity of dissipating power in order to make a measurement.

1.1.1 Thermometer preparation. - As the most important thermal impedance above $10^{-2} \mathrm{~K}$ is the carbon resistive core itself [12] it is advantageous to grind the cylindrical resistor into $0.2 \mathrm{~mm}$ thick longitudinal slabs. The copper leads are kept for electrical and thermal contact [13]. In figure 1 four types of thermometers prepared in our laboratory are shown. Type 1 is similar to those developed by Frossati [14] at the CRTBT in Grenoble. A speer resistor was ground to $0.15 \mathrm{~mm}$ thickness, electrically isolated with cigarette paper and glued with the epoxy resin Stycast 1266 

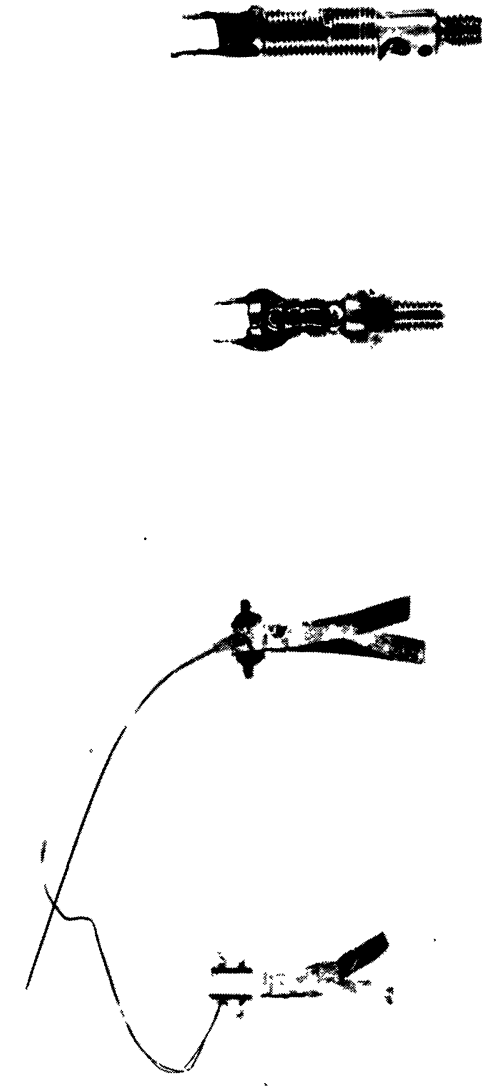

2

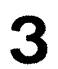

4
Electrical connections were made with a thin $(0.05 \mathrm{~mm})$ superconducting multifilament wire in a cupronickel matrix soldered to the resistor with Sn-In alloy with a low melting point. Type 4 is a compound carbon thermometer (Mat $360 \Omega / * \mathrm{~B} 100 \Omega$ ) with a silver foil. Thermometers so constructed are rugged, small and easily transferred from one position to another without disturbing the calibration.

1.1.2 Instrumentation. - For measuring resistance numerous AC resistance bridges have been reported in the literature. Several commercially available bridges have been used to measure temperatures as low as $5 \mathrm{mK}$ [15]. The bridge network and the amplifier should be constructed in such a way that ground loops and spurious emf caused by moving leads (microphonics) are avoided. The best solution would be to put the entire cryostat and all the measuring equipment into an electrically shielded room, which is not seriously imaginable in a neutron guide hall or in a reactor. It is normally observed that energy absorbed by the thermometer from c.f. fields, mainly generated by radio and TV stations and also by computers located nearby is very serious below $50 \mathrm{mK}$ unless precautions are taken. Without shielding the temperature of the thermometer can increase by a factor of 2 . If it is impossible to build a shielded room low pass filters to earth should be placed in the electrical leads near the resistance thermometer itself. In the author's laboratory filters as proposed by Anderson [4] figure 2 have been used successfully for many years.

Fig. 1. - Modified carbon thermometers : (1) Speer $100 \Omega$ glued into a copper piece, (2) Matsushita $200 \Omega$-Allen Bradley $68 \Omega$ combination glued into a copper piece, (3) Matsushita resistor glued into a folded silver foil, (4) Matsushita $360 \Omega$-Allen Bradley $100 \Omega$ combination glued into a folded silver foil.

into a slit of a cylindrically shaped piece of copper. It was assumed that the epoxy resin would penetrate into the carbon matrix avoiding microcracks during thermal cycling, which could change its $R-T$ characteristics. Isolated copper wires are soldered to the copper leads of the resistor and wound around the thermometer holder for several turns. Electrical connection to the resistor was made to the free ends of the wires, fixed with Stycast 2850 FT onto the holder. The resistor needs never to be warmed above room temperature when changing connections. Type 2 is a compound carbon thermometer consisting of an abreast connection of a Matsushita $200 \Omega$ resistor and a Allen-Breadley $68 \Omega$ resistor, which allows a wide range thermometry between $30 \mathrm{mK}$ and $50 \mathrm{~K}$. Thermometers of type 3 have been used for years for specific heat measurements down to $20 \mathrm{mK}$. Matsushita ERG 18 resistors with a nominal value from 360 to $47 \Omega$ are ground to a thickness of $0.15 \mathrm{~mm}$, and glued with Stycast 1266 in a folded $0.05 \mathrm{~mm}$ thick annealed silver foil, isolated electrically with cigarette paper.

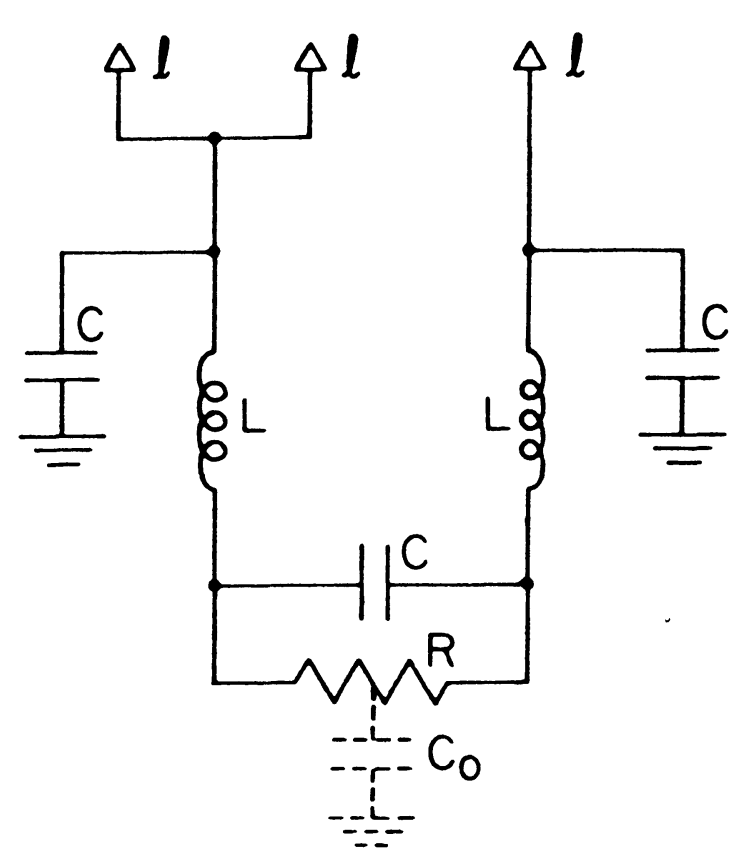

Fig. 2. - Low pass filter designed to prevent heating of resistance thermometers by $\mathrm{rf}$ fields. $\mathrm{R}$ : resistance thermometer, L : inductance (300 turns of $5 \times 10^{-3} \mathrm{~cm}$ diam. superconducting wire (Niomax $\mathrm{CN} / \mathrm{A} 05$ ) on a 0.3 diam.), $\mathrm{C}$ : capacitor $\left(1200 \mathrm{pF}\right.$ silver mica), $\mathrm{C}_{0}$ : capacitance to ground, resulting from thermal grounding of the thermometer, $\ell$ electrical leads to the bridge. 
The stray capacitance is normally increased when one attempts to improve the thermal contact between resistor and its environment. This type of filter shown will remove both normal mode and common mode heating of resistor. With the capacitance present in the circuit it is advisable to operate the bridge at low frequencies $(25 \mathrm{~Hz})$.

Electrical leads to the thermometer must have low thermal conductivity and must be thermally anchored to avoid the spurious transport of heat to the thermometer or to the object to be monitored. The inductance of the low pass filter if placed on the mixing chamber can provide an excellent thermalisation of the electrical leads.

1.1.3 Temperature dependence. - The $R-T$ characteristics of thermometers of type 3 with different nominal values $(47 \Omega, 100 \Omega$ and $200 \Omega$ below $4 \mathrm{~K}, 0.2 \mathrm{~mm}$ thick) are shown in figure 3 . The calibration was made with a germanium thermometer (Cryocal),

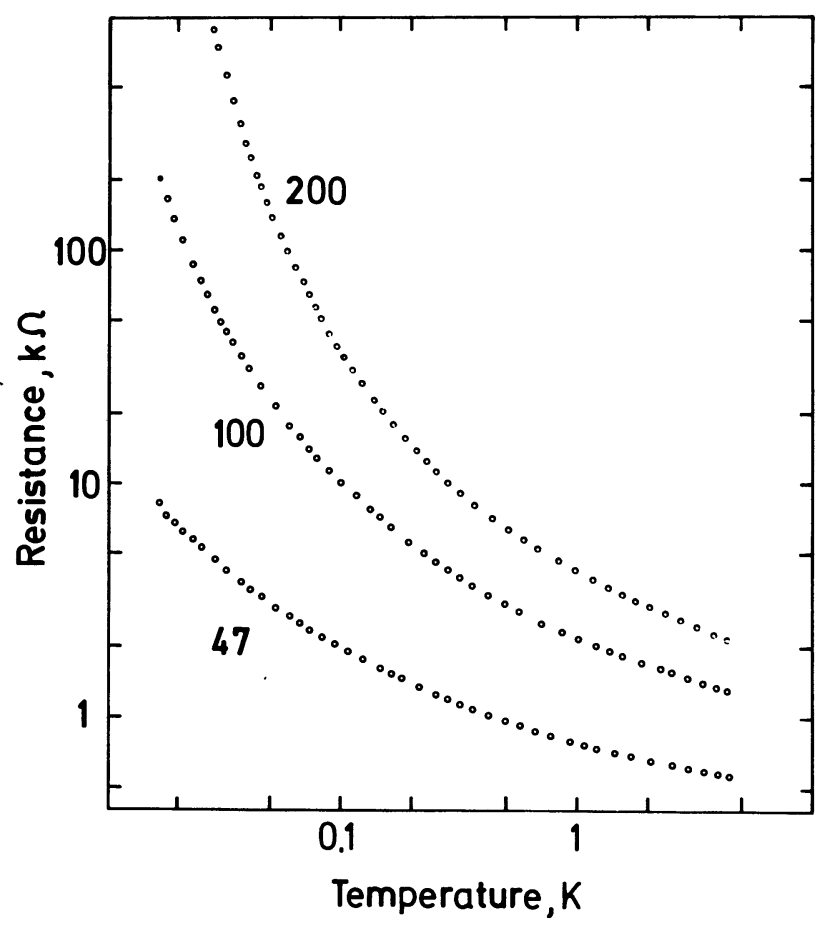

Fig. 3. - $R-T$ characteristics of modified Matsushita resistors of different nominal values (47 $\Omega, 100 \Omega, 200 \Omega$ ).

which was calibrated with a $\mathrm{CMN}$ and a noise thermometer down to $15 \mathrm{mK}$ and recently verified with a NBS Standard. The most striking feature is the steadily increasing sensitivity with falling temperature. For thermometers made of $47 \Omega$ Matsushita resistors we have observed this effect down to $7.5 \mathrm{mK}$ [16] as can be seen in figure 4 .

No saturation effects have been observed. In our opinion this is due to the construction of the thermometer, to the use of cold filters and to an apparent better thermal conductivity of the carbon matrix

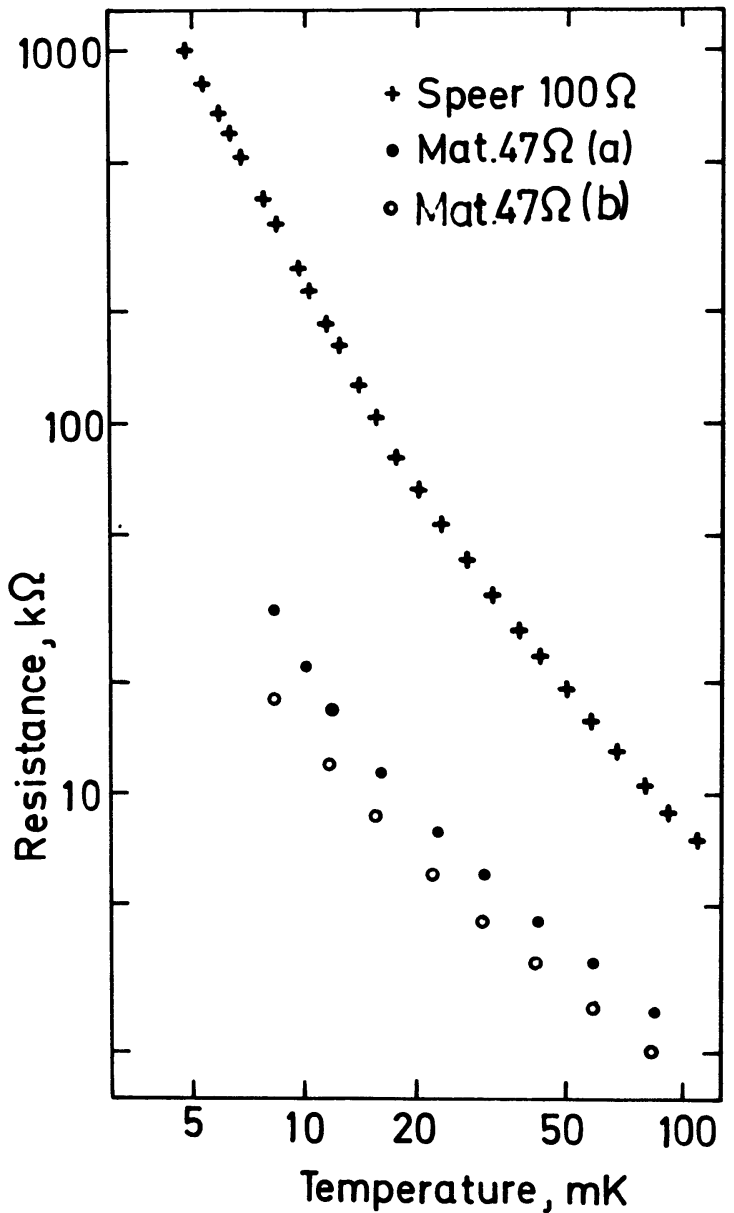

Fig. 4. $-R-T$ characteristics of modified Speer $100 \Omega$ and Matsushita $47 \Omega$ resistors. The Speer $100 \Omega$ and the Matsushita $47 \Omega$ (a) were measured with a cold filter and the Matsushita $47 \Omega$ (b) only with a filter at the top of the cryostat.

of Matsushita resistors as compared to Speer resistors [17].

In varying the measuring power it was observed that the relative temperature increase $\Delta T / T$ due to self heating is less than $10^{-3}$ if $Q<10^{-8} \mathrm{~T}^{3} \mathrm{~W}$.

There exists no simple theoretical or empirical relation between temperature $T$ and resistance $R$. The hopping law proposed by Anderson et al. [18]

$$
R=R_{0} \exp \left(A T^{-1 / 4}\right)
$$

does not fit our data obtained with the modified Matsushita resistors due to the large increase of the slope and with falling temperatures. The best results were obtained with the power series

$$
1 / T=\sum_{i=0}^{n} a_{i}(\ln R)^{i} \quad \text { (all } a_{i} \text { constant) }
$$

proposed by Star et al. [19], with $n=4$ or 5 .

Figure 5 shows the characteristics of compound carbon thermometers. These small thermometers are usefull over a very wide temperature range. We used the combination Mat $200 \Omega / \mathrm{AB} 68$ for thermal 


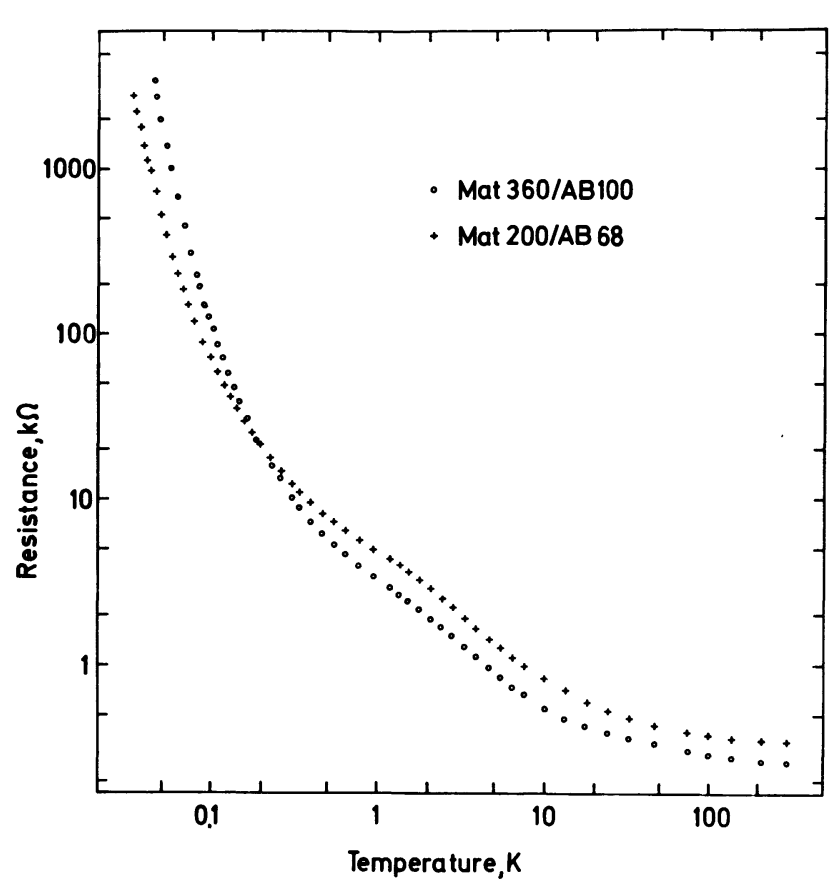

Fig. 5. - $R-T$ characteristics of compound carbon thermometers : Mat $200 \Omega / \mathrm{AB} 68 \Omega$ and Mat $360 \Omega / \mathrm{AB} 100 \Omega$.

conductivity and energy release measurements from $40 \mathrm{mK}$ up to $20 \mathrm{~K}$.

Comparing Speer and Matsushita resistors it seems that the latter are less influenced by self heating.

1.1.4 Stability. - We observed that thermometers made of Matsushita resistors which did not change their $4 \mathrm{~K}$ value after several $(10 \times)$ cyclings between room temperature will retain their calibration within $1 \%$ over years. Sometimes a small change in calibration at high temperatures (above $0.3 \mathrm{~K}$ ) and none at the lowest temperature was observed [20]. It could be explained by a. small change of the contact resistance between copper leads and the carbon matrix. It is therefore prudent to check the calibration after each cooldown, at least at $4.2 \mathrm{~K}$.

1.1.5 Magnetic field dependence. - We did not study the magnetic field dependence of Matsushita resistors. Amaya et al. [21] used Matsushita resistors down to $50 \mathrm{mK}$ in a field of $1 \mathrm{~T}$. He found a relative change of the resistance $\Delta R / R$ of up to $7 \%$, which is apparently of the same order as it was found for Speer resistors by Sanchez et al. [22] and Thompson et al. [23]. In our laboratory Chr. Probst observed that thermometers with thin slabs of Matsushita resistors show a variation of less than $8 \%$ in fields up to $5 \mathrm{~T}$ and temperatures down to $50 \mathrm{mK}$ [24]. This value also depends on the orientation of the resistor with the magnetic field. If one wants to avoid carbon resistors as thermometers in magnetic fields, it is possible to use capacitive thermometers which are not affected even by large magnetic fields. But the bridge and the leads should be carefully constructed, with electrical guards extending through all feedthroughs and to the thermometer [25].

1.2 Germanium thermometer. - Since 1970 we have used in our laboratory germanium thermometers provided by Cryocal down to $15 \mathrm{mK}$. Their reproducibility is excellent, but their sensitivity to power dissipation is at least an order of magnitude higher than that of Matsushita resistors. A new type of germanium resistor is produced by Lake Shore Cryotronics [8] which is apparently less sensitive to power dissipation. Roth et al. [31] estimate that the measuring power $\dot{Q}$ that can be tolerated for a fractional temperature change of $\Delta T / T=10^{-3}$ should be roughly $\dot{Q}=3 \times 10^{-7} \mathrm{~T}^{4.5} \mathrm{~W}$. It seems worthwhile to use germanium resistors at moderately low temperatures $(T>30 \mathrm{mK})$ as a reliable temperature standard.

\section{Heat transfer at low temperature.}

If the experimental temperature is reduced below $\mathrm{i} K$ it becomes progressively more difficult to find satisfactory solutions to problems associated with heat transfer. In neutron scattering studies these difficulties are amplified by the fact that most of the materials with a good thermal conductivity such as copper or silver have large absorption or scattering crossections. Their use must therefore be carefully examined.

To start with, heat conductivity data of materials important for design purposes and some values' of thermal boundary resistance at the interface between two materials are presented. Later on some examples of experimental setups are discussed. In figure 6 values of heat conductivity are presented. The highest conductivity, $k<1000 \mathrm{~T} \mathrm{~W} / \mathrm{K}^{2} \mathrm{~m}$ has been found for pure, well annealed copper and silver. For commercial copper wires $k=300 \mathrm{~T} \mathrm{~W} / \mathrm{K}^{2} \mathrm{~m}$ may be obtained. OFHC (oxygen free high conductivity) copper, which is often used for heat connectors below $1 \mathrm{~K}$, has a $k$ of $50-150 \mathrm{TW} / \mathrm{K}^{2} \mathrm{~m}$. Aluminium is used for experimental cells in neutron scattering studies, due to its extremely low crossection for neutrons. High purity aluminium shows a conductivity $k=400 \mathrm{~T} \mathrm{~W} / \mathrm{K}^{2} \mathrm{~m}$ in the normal state. For aluminium alloys $k$ decreases dramatically. Coccia and Niinikoski [26] report for the aluminium alloy $\mathrm{Al} 5056$ (with $5.2 \% \mathrm{Mg}, 0.1 \% \mathrm{Mn}$, $0.1 \% \mathrm{Co}) k=1 \mathrm{~T} \mathrm{~W} / \mathrm{K}^{2} \mathrm{~m}$. But in the superconducting state below $0.2 \mathrm{~K}$ pure $\mathrm{Al}$ and the alloy show nearly the same thermal conductivity $\left(k=3 \mathrm{~T}^{3} \mathrm{~W} / \mathrm{K}^{4} \mathrm{~m}\right)$. In the superconducting state well below $T_{\mathrm{c}}(\sim 1.4 \mathrm{~K})$, heat is transported only by phonons. At these temperatures phonons are scattered only by grain boundaries, which are nearly independent of sample purity.

For comparison the data for brass, stainless steel, $\mathrm{CuNi}$ and manganin are also given.

In the discussion, the values for In in the normal $\left(550 \mathrm{~T} \mathrm{~W} / \mathrm{mK}^{2}\right)$ and in the superconducting state $\left(21 \mathrm{~T}^{3} \mathrm{~W} / \mathrm{K}^{4} \mathrm{~m}\right)$ are needed [27]. This value is close to that of CMN single crystals. 


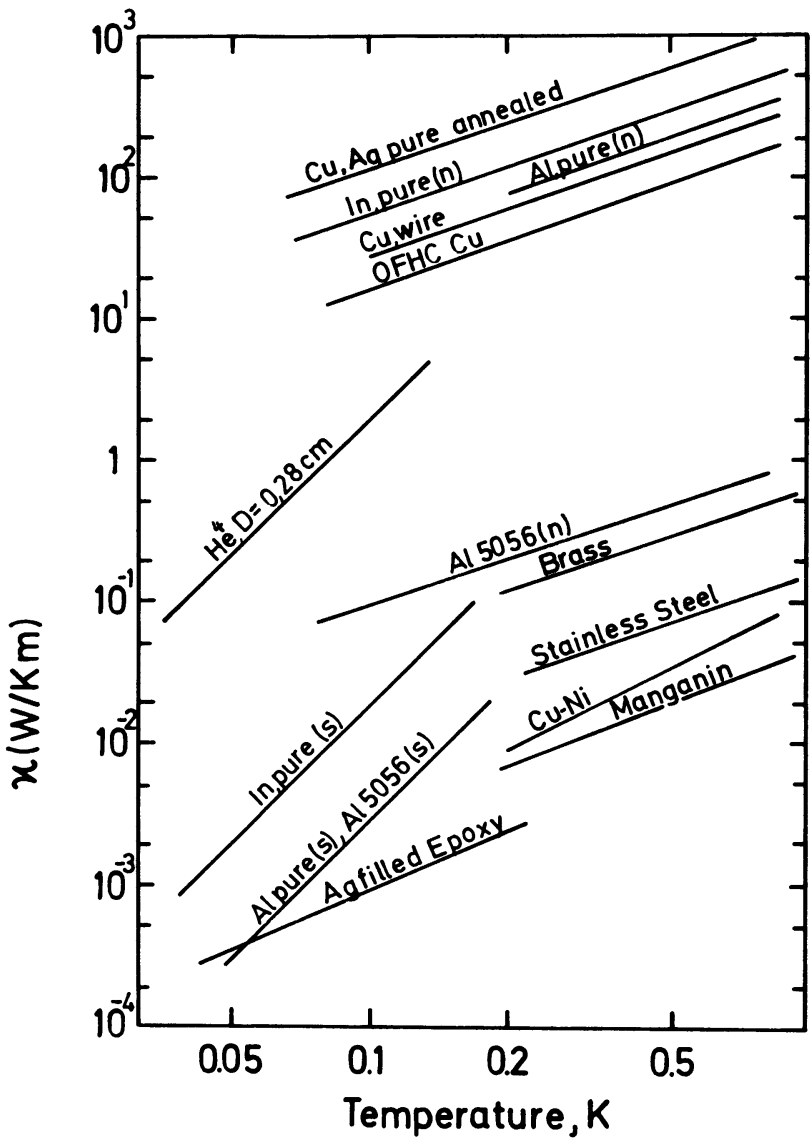

Fig. 6. - The thermal conductivity of materials important for neutron scattering studies at low temperatures.

The thermal conductivity of $\mathrm{He}^{4}$ shows at $0.6 \mathrm{~K}$ a clear bend (Fig. 7). Above this temperature heat is transported by a convective counter flow of superfluid and normal helium. Below this temperature

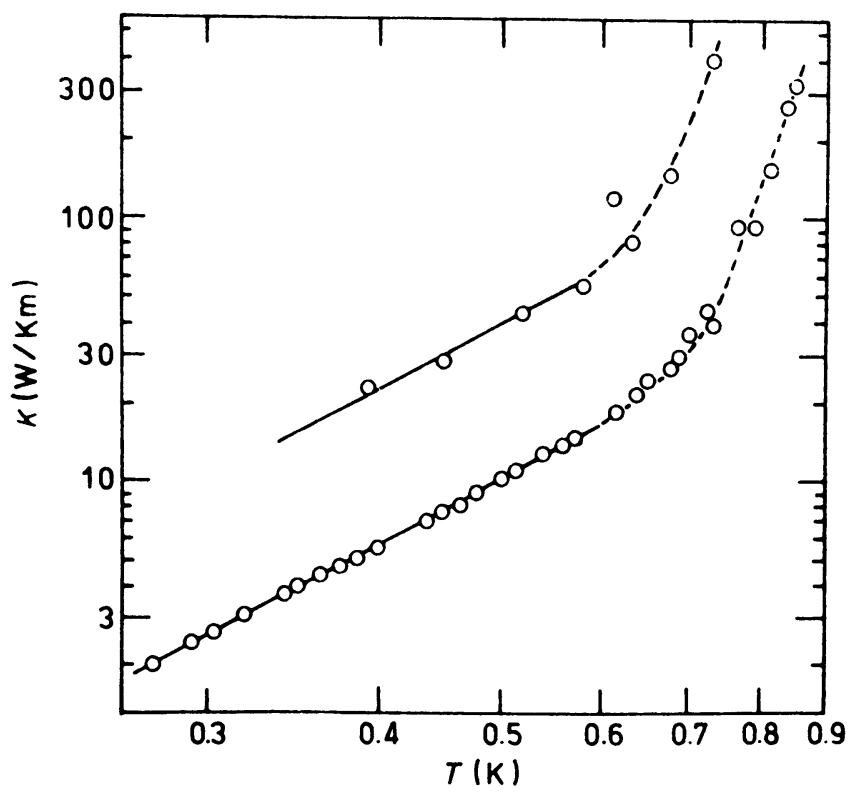

Fig. 7. - The thermal conductivity of liquid $\mathrm{He}^{4}$ in two tubes, $0.8 \mathrm{~mm}$ (upper curve) and $0.29 \mathrm{~mm}$ (lower curve) in diam. respectively (Fairbanks and Wilks, 1955). this process becomes negligible and heat transport by phonons dominates. The data of Fairbanks and Wilks [28] can be interpreted with the formula

$$
k=3 \times 10^{5} D T^{3}(2-f) / f \mathrm{~W} / \mathrm{K}^{4} \mathrm{~m}^{2}
$$

where $D$ is the diameter of the $\mathrm{He}^{4}$ column and $f$ the fraction of phonons diffusely reflected by the walls. Reynolds et al. [29] proposed a silver filled epoxy resin as bonding-agent between two metals. They measured a thermal conductivity below $0.3 \mathrm{~K}$ of $k=2 \times 10^{-2} \mathrm{~T} \mathrm{~W} / \mathrm{mK}^{2}$.

A serious problem at low temperatures is the thermal contact resistance, often called Kapitza resistance, which is defined by $R_{\mathrm{K}}=\Delta T / A \dot{Q}(\Delta T \leqslant T)$, where $A$ is the surface.

Because acoustic mismatch limits the transmission of phonons between the two materials at the interfaces of insulators, it varies as $T^{-3}$ and thus presents an impedance to the heat flow at $0.01 \mathrm{~K}$, which is by a factor of $10^{6}$ larger than at $1 \mathrm{~K}$. Various glues and greases are often employed to achieve thermal contact between two solids. Anderson and Peterson [30] have investigated several bonding agents such as Apiezon N grease, General Electronic 7031 varnish, Epibond 121 below $1 \mathrm{~K}$. They show that the total resistance $R_{\mathrm{T}}$ can be written as a boundary resistance $R_{\mathrm{K}}$ at both interfaces plus the bulk phonon resistance of the bonding agent, i.e. that $R_{\mathrm{T}}=2 R_{\mathrm{K}}+R_{\mathrm{P}}$ with $R_{\mathrm{K}}=7.5 \times 10^{-4} \mathrm{~T}^{-3} \mathrm{~K}^{4} \mathrm{~m}^{2} / \mathrm{W} \pm 20^{\circ}{ }_{0}$.

The second term $R_{\mathrm{p}}=K / k A$ is of little importance below $0.5 \mathrm{~K}$ if the thickness $L$ of the layer can be made $10 \mu \mathrm{m}$ or less.

The values for $R_{\mathrm{K}}$ between liquid $\mathrm{He}^{4}$ and solids are larger and vary between $5 \times 10^{-3}\left(\mathrm{~K}^{4} \mathrm{~m}^{2} / \mathrm{W}\right)$ for CPA crystals and $2 \times 10^{-2}\left(\mathrm{~K}^{4} \mathrm{~m}^{2} / \mathrm{W}\right)$ for copper.

In metal to metal contacts the heat transfer is electronic. The boundary conductance can be determined by measuring the electronic conductance at low temperatures and by employing the WiedemannFranz law

$$
k / \sigma=\pi^{2} K^{2} T / 3 e^{2}=\alpha T, \alpha=2.5 \times 10^{-8} \mathrm{~W} \Omega / \mathrm{K}^{2} .
$$

Electrical contact resistances of $1 \mu \Omega$ are easily realisable corresponding to $k \approx 2.5 \times 10^{-2} \mathrm{~T} \mathrm{~W} / \mathrm{K}^{2}$, a value rarely obtained with dielectric bonding agents below $0.1 \mathrm{~K}$. Of course, this statement is not valid if one of the metals is in the superconducting state because in this case heat is transported only by phonons. In thermal contacts made of soldered indium the problem may be overcome by applying a magnetic field bringing In into the normal state.

With these informations about heat transfer some experimental set ups will be discussed. The first one is an experiment on $\mathrm{IN} 12$ with $\mathrm{Nb}$ single crystals doped with both $\mathrm{O}$ and $\mathrm{H}$, looking for the tunnelling mode of trapped $\mathrm{H}$. The niobium single crystals are 
fixed via an Al-plate onto the bottom of the mixing chamber (Fig. 8). To improve the thermal contact the interfaces are covered with Fomblin, a synthetic hydrogen free oil based on fluor carbons, with small absorption and scattering neutron cross section. It is supposed that it shows a boundary resistance similar to the bonding agents discussed previously.

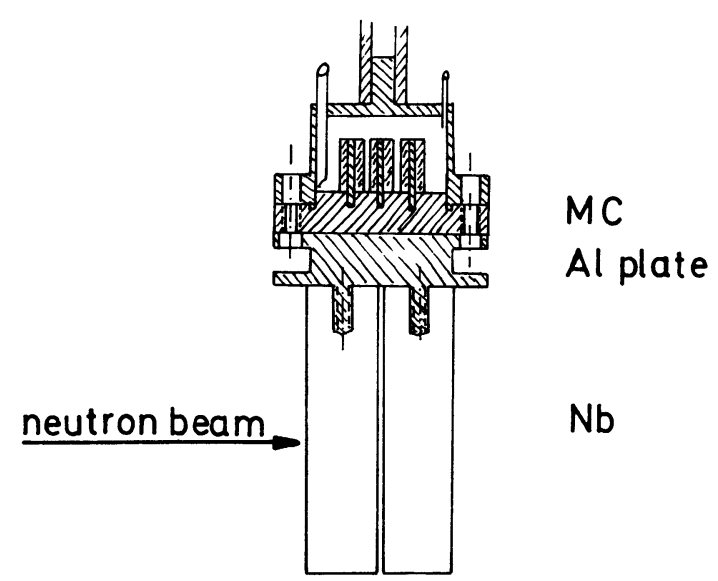

Fig. 8. - Experimental set up for Nb single crystals.

The thermal resistance $R_{\text {tot }}$ between the mixing chamber and the sample is the sum of

$R_{\mathrm{MC}-\mathrm{Al}}$ (contact resistance between mixing chamber and Al plate)

$$
\simeq 2 \mathrm{~T}^{-3} \mathrm{~K}^{4} / \mathrm{W}
$$

$R_{\mathrm{Al}} \quad$ (thermal resistance of the Al-plate)

$$
\sim 40 \mathrm{~T}^{-3} \mathrm{~K}^{4} / \mathrm{W}
$$

$R_{\mathrm{Al}-\mathrm{Nb}}$ (contact resistance between Al-plate and $\mathrm{Nb}$ )

$$
\simeq 5 \mathrm{~T}^{-3} \mathrm{~K}^{4} / \mathrm{W}
$$

$R_{\mathrm{Nb}} \quad$ (thermal resistance of $\mathrm{Nb}$ )

$$
\simeq 30 \mathrm{~T}^{-3} \mathrm{~K}^{4} / \mathrm{W} \text {. }
$$

The thermal resistance of the Al plate and of the sample are dominating.

In the experiment the temperature of the mixing chamber and the Al plate have been measured. In order to keep the backround low, the thermometer on the sample was removed. With no neutrons the mixing chamber and the Al plate reached a final temperature of $45 \mathrm{mK}$ and $55 \mathrm{mK}$, respectively, whereas after opening the neutron beam $\left(10^{7}\right.$ neutrons $\mathrm{cm}^{-2} \mathrm{~s}^{-1}$ ) the temperatures increased to 80 and $110 \mathrm{mK}$. This corresponds to a dissipation of $3 \mu \mathrm{W}$ in the sample. This could be verified by a simulation experiment in heating the sample.

The origin of this dissipation must be a nuclear reaction of the neutron with niobium. It is known that $\mathrm{Nb}^{93}$ captures neutrons yielding $\mathrm{Nb}^{94}$. The latter decays with a halflife of $6 \mathrm{~min}$ to its ground state via the emission of $40 \mathrm{keV} \gamma$-rays. The main heating arises from conversion electrons due to these $\gamma$-rays. For a flux of $10^{7}$ thermal neutrons $\mathrm{cm}^{-2} \mathrm{~s}^{-1}$ and $200 \mathrm{gr} \mathrm{Nb}$ a saturation activity of $200 \mu \mathrm{c}$ is expected, corresponding to a heat load of $\sim 2.5 \mu \mathrm{W}$ [32], approximatively the same as observed in the experiment. The same effect has been observed in neutron scattering studies on praseodymium samples with an even larger heat load, arising from conversion electrons due to $740 \mathrm{keV}$ $\gamma$-ray. This signifies that heat dissipation due to neutron absorption should be carefully studied before starting a neutron scattering experiment at very low temperatures.

Another experimental setup shown in figure 9 is used to study powders or liquids in an aluminium (A5) cell with a volume of $50 \times 28 \times 2 \mathrm{~mm}$. For an experiment on IN13 the cell was filled with $\mathrm{Mn}\left(\mathrm{CH}_{3} \mathrm{COO}\right)_{2} .4 \mathrm{H}_{2} \mathrm{O}(1.4 \mathrm{gr}$, filling factor $30 \%)$ to study rotational tunnelling of the methyl group.

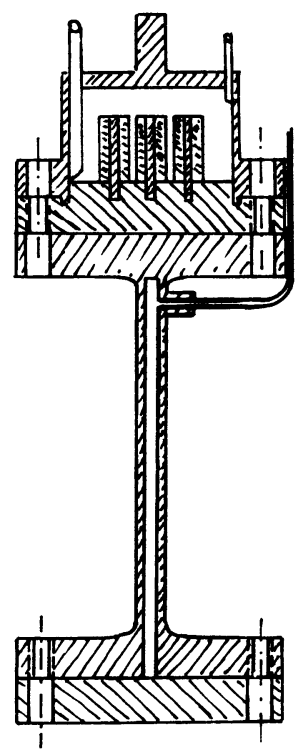

Fig. 9. - Experimental set up for powders and liquids.

With a mean particle size of $0.1 \mathrm{~mm}$ a surface of $300 \mathrm{~cm}^{2}$ was estimated. To improve the thermal contact of the powder with the cell $\mathrm{He}^{4}$ was condensed in the cell. The thermal resistance between the mixing chamber and the sample is the sum of the following terms :

$R_{\mathrm{MC}-\mathrm{Al}} \quad$ (contact resistance between mixing chamber and the cell)

$$
\sim 2 \mathrm{~T}^{-3} \mathrm{~K}^{4} / \mathrm{W}
$$

$R_{\text {cell }} \quad$ (thermal resistance of the cell)

$$
150 \mathrm{~T}^{-3} \mathrm{~K}^{4} / \mathrm{W}
$$

$R_{\text {cell }-\mathrm{He}^{4}}$ (boundary resistance cell- $\mathrm{He}^{4}$ )

$$
7 \mathrm{~T}^{-3} \mathrm{~K}^{4} / \mathrm{W}
$$


$R_{\mathrm{He}^{4}} \quad$ (thermal conductivity of $\mathrm{He}^{4}$ )

$$
0.1 \mathrm{~T}^{-3} \mathrm{~K}^{4} / \mathrm{W}
$$

$R_{\mathrm{He}^{4}-\text { sample }}$ (boundary resistance)

$$
3 \times 10^{-2} \mathrm{~T}^{-3} \mathrm{~K}^{4} / \mathrm{W}
$$

$R_{\text {sample }} \quad$ (thermal conductivity of the sample)

$$
50 \mathrm{~T}^{-3} \mathrm{~K}^{4} / \mathrm{W} \text {. }
$$

As in the previous example the main bottleneck is the thermal conductivity of aluminium. Whenever possible one should avoid aluminium in the thermal path. A solution of this problem could be a direct contact of the bottom of the mixing chamber with $\mathrm{He}^{4}$ via a heat exchanger of sintered copper.

In conclusion, the lower the temperature the higher the effort and care required in preparing a neutron scattering experiment. Especially, heat dissipation due to neutron absorption and bottlenecks in the thermal paths should be evaluated carefully before starting the experiment. Neutron beam time is too expensive to be wasted.

\section{References}

[1] White, G. K., Experimental Techniques in Low Temperature Physics (Clarendon, Oxford) 1979.

[2] LounasmaA, O. V., Experimental Principles and Methods below $1 \mathrm{~K}$ (Academic Press, New York) 1974.

[3] Betrs, D. S., Refrigeration and Thermometry below $1 \mathrm{~K}$ (Crane-Russak, New York) 1976.

[4] Instrumentation at Temperatures below $1 \mathrm{~K}$, ANDERSON, A. C., Rev. Sci. Instrum. 51 (12) (1980).

[5] Thermometry at Ultralow Temperatures, WEYHMANN, W. in Methods of Experimental Physics, edited by R. V. Coleman (Academic Press, New York) 1974, Vol. 11, p. 485.

[6] Recent Advances in Thermometry below $300 \mathrm{mK}$, Hudson, R. P., Marshak, H., Soulen, R. J., Utton, I. and D. B., J. Low Temp. Phys. 20 (1975) 1.

[7] Anderson, A. C., Carbon Resistance Thermometry, in "Temperature, Its Measurement and Control in Science and Industry ». Based on the 5th Temp. Symp. Washington, D. C., Instr. Soc. Ann., Pittsburgh, 1973.

[8] Lake Shore Cryotronics Inc., P. O. Box 29876, Columbus, OH 43229 USA.

[9] Frossati, G., Imbert, D., Peccond, L., Thoulouze, D. and WAKSMANN, B. in Low Temperature Physics LT-14, edited by D. Krusius and M. Vuonio (North Holland, Amsterdam) 1975, Vol. 4, p. 80 .

[10] Steinbeck, M., Anthony, P. J., Anderson, A. C., Rev. Sci. Instrum. 49 (1978) 671

[11] Brooks, J. S., Rubin, L. G., Francis Bitter National Magnet Lab. MIT, Cambridge, MA 02139, USA.

[12] Oda, Y., Fuji, G. and Nagano, H., Cryogenics 14 (1974) 84.

[13] Robichaux, J. E. Jr and Anderson, A. C., Rev. Sci. Instrum. 40 (1969) 1512.
[14] Sanchez, J., Benoit, A., Flouquet, J., Frossati, G., J. Physique Colloq. 35 (1974) C1-23.

[15] Ste Barras-Provence, Grenoble France. RV Elek'tronikka, Oy, Finland. SHE Corporation, San Diego, USA.

[16] Eska, G. and Neumaier, K., Cryogenics 23 (1983) 84.

[17] Kobayasi, S., Shinohara, M. and Ono, K., Cryogenics 16 (1976) 597.

[18] Anderson, A. C., Anderson, J. H. and Zaitlin, M. P., Rev. Sci. Instrum. 47 (1976) 407.

[19] Star, N. M., van Dam, J. E., van BaARle, C., $J$. Phys. E 2 (1969) 257.

[20] Soulen, R., NBS Washington, H. Godfrin CNRS/ CRTBT, Grenoble, K. Guckelsberger PTB Braunschweig (private communication).

[21] Amayo, K., Keesom, P. H. and Wenger, L. E., Phys. Rev. B 16 (1977) 1042.

[22] Sanchez, J., Benoit, A. and Flouquet, J., Rev. Sci. Instrum. 48 (1979) 1090.

[23] Thompson, J. R. and Thomson, J. O., Rev. Sci. Instrum. 48 (1977) 1713.

[24] Probst, Chr., private communication.

[25] Prober, D. E., Rev. Sci. Instrum. 50 (1979) 387.

[26] Coccia, E. and Ninikoski, T. O., J. Phys. E 16 (1983) 695.

[27] March, R. H. and Symko, O. G., Proc. Grenoble Conf. Int. Inst. of Refriger, Annexe 2, p. 57.

[28] Fairbanks, H. A. and Wilks, J., Proc. R. Soc. Ser. A 231 (1955) 545.

[29] Reynolds, C. L. and Anderson, A. C., Rev. Sci. Instrum. 48 (1977) 1715.

[30] Anderson, A. C. and Peterson, R. E., Cryogenics 10 (1970) 430.

[31] Roth, E. P., Matey, J. R., Anderson, A. C. and JoHn, D. A., Rev. Sci. Instrum. 49 (1978) 813.

[32] Eska, G., Hagn, E. and ZeCH, E., Phys. Dep. TUM, Garching. 